\section{Cataract surgery in patients with uveitis}

Cataract is known to develop frequently in eyes with uveitis, with an incidence as high as $50 \%$ in cases of Fuchs' heterochromic cyclitis (FHC) and pars planitis. ${ }^{1,2}$ Uveitis patients have a turbulent post-operative course with a high incidence of recurrent inflammation and postoperative complications. The following review presents guidelines relating to some of the difficulties in treating these patients. For a more detailed discussion the reader is encouraged to refer to recent texts by Alio and Chinpoint ${ }^{3}$ and Lightman and Towler. ${ }^{4}$ In this article, patients are divided into 'anterior' and 'posterior' disease groups based on the anatomical location of the main focus of ocular inflammation. The usefulness of a standardised regimen of preoperative steroids is discussed as this has been proven in patients with a diverse set of uveitis diagnoses. ${ }^{5,6}$

\section{Cataract surgery in eyes with anterior uveitis diagnoses}

Patients with anterior disease usually do not need systemic steroid prophylaxis unless these drugs have already formed part of the management of the condition, e.g. for treatment of macular oedema. Those with chronic anterior uveitis (CAU, excluding Fuchs' heterochromic cyclitis), however, whether quiescent or active, should be treated with systemic steroids preoperatively, unless contraindicated. Patients from the Indian subcontinent with anterior disease demonstrate a higher incidence of macular oedema and should be considered for prophylactic steroid treatment irrespective of their anterior uveitis diagnosis.

In a recent study, $33 \%$ of patients in the anterior disease group had previously required systemic steroids and were thus treated with prophylaxis prior to cataract surgery. ${ }^{6}$ In this group of patients, $96 \%$ of cases demonstrated an improvement in vision (median +4 Snellen lines) with $64 \%$ having a visual acuity of $6 / 12$ or better at 6 months. In those with anterior disease, severe uveitis in the first week postoperatively was found to be associated with an increased incidence of macular oedema, and visual acuity less than $6 / 12$ at 6 months followup. ${ }^{6}$ Patients with FHC (with no steroid prophylaxis) have the least problematic postoperative course and the best visual outcomes. ${ }^{7,8}$
NARCISS OKHRAVI, HAMISH M.A. TOWLER, SUSAN L. LIGHTMAN

The percentage of cases with posterior capsule opacification (PCO) and subsequently requiring $\mathrm{Nd}-\mathrm{YAG}$ capsulotomy was highest in patients with acute anterior uveitis. Other authors have reported overall rates of PCO in a heterogeneous group of pseudophakic uveitis patients as $23 \%$ ( $n=16$ eyes; $10 / 16$ proceeded to Nd-YAG) ${ }^{9}$ and $7 \%\left(n=27\right.$ eyes). ${ }^{10}$ More recently Dana et al. ${ }^{11}$ have reported a rate of $54 \%$ over a mean follow-up of 4.3 years and an association between young age and increased incidence of PCO. The percentage of cases developing PCO in our recent study was noted to be $49 \%(n=90)$, with $66 \%$ of these requiring Nd-YAG capsulotomy over a mean follow-up of 10 months. ${ }^{6}$ PCO is more likely to occur in eyes with persistent inflammatory activity, and is also dependent on the material and design of the intraocular lens, and the degree of contact between the optic and the posterior capsule. PMMA lenses have demonstrated the highest incidence of associated PCO in normal eyes and, since the level of inflammatory activity is higher in eyes with uveitis, perhaps this material is not ideal for use in patients with uveitis. ${ }^{12,13}$

\section{Cataract surgery in eyes with posterior uveitis diagnoses}

In contrast to patients with anterior uveitis diagnoses, $97 \%$ of patients in the posterior disease group required and were treated with systemic steroid prophylaxis prior to cataract surgery. ${ }^{6}$ In this group of patients, $81 \%$ of cases demonstrated an improvement in vision (median +4 Snellen lines) but only $46 \%$ demonstrated a visual acuity of $6 / 12$ or better at 6 months. In the posterior disease group, a poor visual outcome was noted to be most commonly the result of vision-limiting conditions present pre-operatively. ${ }^{5,6,14}$ Patients with pars planitis (with steroid prophylaxis) have the least problematic post-operative course and the best visual outcomes. ${ }^{6,14,15}$ All patients with posterior disease should be treated with prophylactic systemic steroids pre-operatively, unless contraindicated.

\section{Suggested management}

Pre-operatively, ocular inflammation should be controlled as well as possible for a minimum of 6 weeks. ${ }^{4,6,9,10}$ The reduced post-operative inflammation following phacoemulsification
N. Okhravi

S.L. Lightman Department of Clinical Ophthalmology Moorfields Eye Hospital and

The Institute of Ophthalmology London, UK

H.M.A. Towler Department of Ophthalmology Whipps Cross Hospital London, UK

Miss Narciss Okhravi, BSc, FRCOphth, PhD

Department of Clinical Ophthalmology

The Institute of Ophthalmology and University College London Bath Street London EC1V 9EL, UK

Tel: +44 (0)171566 2266 Fax: +44 (0)1712519350 e-mail:

nokhravi@hgmp.mrc.ac.uk

Received: 15 November 1999 Accepted in revised form: 14 April 2000 
suggests that this technique may be more suitable in uveitic eyes undergoing cataract surgery. ${ }^{16-18}$ Studies using phacoemulsification have already been reported. ${ }^{19,20}$ Immediate post-operative management should include review and discharge with topical steroid (betamethasone, dexamethasone or prednisolone acetate), antibiotic and mydriatic drops in addition to systemic steroids where used. The frequency of topical steroid treatment is dependent on the clinical findings. This may be increased to hourly in complicated cases and especially in eyes which have undergone extensive perioperative iris manipulation. Fibrin in the anterior chamber is an indication for more intensive topical therapy and prompt use of recombinant tissue plasminogen activator (rTPA, $10 \mu \mathrm{g}$ ), especially if the fibrin occludes the visual axis. ${ }^{21,22}$

The regimen of systemic steroids used for control of pre- and post-operative inflammation varies widely. ${ }^{14,23,24}$ A standardised regimen has recently been reported which results in improved control of inflammation in these high-risk eyes. ${ }^{6}$ Prednisolone $0.5 \mathrm{mg} / \mathrm{kg}$ per day is used for 2 weeks pre-operatively and the dose gradually reduced by $5 \mathrm{mg}$ /day every week (depending on the severity of inflammation and/or bilaterality of the disease), usually starting at the beginning of the second post-operative week. ${ }^{6}$ Patients receiving systemic steroids should routinely undergo blood pressure measurement, urinalysis and random blood glucose monitoring at every clinic visit.

The progress of each patient should be carefully monitored in the months following surgery. Treatment options for severe uveitis (defined as $\geqslant 3+$ cells per highpower slit-lamp beam \pm fibrin in the anterior chamber) and macular oedema include orbital floor steroid injections and systemic steroids, which should be added or increased according to need. Macular oedema should be diagnosed clinically in the first instance. In cases in which some doubt remains, fluorescein angiography is performed to establish the diagnosis. Although oral acetazolamide may be of benefit in the treatment of macular oedema following cataract surgery, ${ }^{25}$ experience has shown it to be of little use in uveitis and the mainstay of treatment for unilateral macular oedema is orbital floor steroid injections (methylprednisolone $40 \mathrm{mg}+$ betamethasone $4 \mathrm{mg}$ ). However, in the presence of raised intraocular pressure, bilateral disease or patient preference, systemic steroids should be used. If the patient is already taking systemic steroids at the time of diagnosis of macular oedema, the dose should be increased only if the fundal appearance and reduction in visual acuity are clinically significant or the condition is bilateral.

\section{References}

1. Franceschetti A. Hetrochromic cyclitis (Fuchs' syndrome). Am J Ophthalmol 1955;39:50-8.

2. Liesegang TJ. Clinical features and prognosis in Fuchs' uveitis syndrome. Arch Ophthalmol 1982;100:1622-6.

3. Alio JL, Chinpoint E. Surgery of cataract in patients with uveitis. Dev Ophthalmol 1999;31:167-74.
4. Lightman S, Towler HMA. Uveitis. London: BMJ Publishing Group, 1998

5. Barton K, Hall AJH, Rosen PH, Cooling RJ, Lightman S. Systemic steroid prophylaxis for cataract surgery in patients with posterior uveitis. Ocular Immunol Inflamm 1994;2:297-16.

6. Okhravi N, Lightman S, Towler HMA. Assessment of visual outcome after cataract surgery in patients with uveitis. Ophthalmology 1999;106:710-22.

7. Gee SS, Tabbara KF. Extracapsular cataract extraction in Fuchs' heterochromic iridocyclitis. Am J Ophthalmol 1989;108:310-4.

8. O'Neill D, Murray PI, Patel BC, Hamilton AM. Extracapsular cataract surgery with and without intraocular lens implantation in Fuchs' heterochromic cyclitis. Ophthalmology 1995;102:1362-8.

9. Chung YM, Yeh TS. Intraocular lens implantation following extracapsular cataract extraction in uveitis. Ophthalmic Surg 1990;21:272-6.

10. Foster CS, Fong LP, Singh G. Cataract surgery and intraocular lens implantation in patients with uveitis [see comments]. Ophthalmology 1989;96:281-8.

11. Dana MR, Chatzistefanou K, Shaumberg DA, Foster CS. Posterior capsule opacification after cataract surgery in patients with uveitis. Ophthalmology 1997;104:1387-94.

12. Hayashi H, Hayashi K, Nakao F, Hayashi F. Quantitative comparison of posterior capsule opacification after polymethylmethacrylate, silicone, and soft acrylic intraocular lens implantation. Arch Ophthalmol 1996;116:1579-82.

13. Apple DJ, Solomon KD, Tetz MR, Assia EI, Holland EY, Legler UF, Tsai JC, et al. Posterior capsule opacification. Surv Ophthalmol 1992;37:73-116.

14. Hooper PL, Rao NA, Smith RE. Cataract extraction in uveitis patients. Surv Ophthalmol 1990;35:120-44.

15. Kaufman AH, Foster CS. Cataract extraction in patients with pars planitis. Ophthalmology 1993;100:1210-7.

16. Pande MV, Spalton DJ, Kerr-Muir MG, Marshall J. Postoperative inflammatory response to phacoemulsification and extracapsular cataract surgery: aqueous flare and cells. J Cataract Refract Surg 1996;22(Suppl 1):770-4.

17. Oshika T, Yoshimura K, Miyata N. Post-surgical inflammation after phacoemulsification and extracapsular extraction with soft or conventional intraocular lens implantation. J Cataract Refract Surg 1992;18:356-61.

18. Chee SP, Ti SE, Sivakumar M, Tan DT. Post-operative inflammation: extracapsular cataract extraction versus phacoemulsification. J Cataract Refract Surg 1999;25:1280-5.

19. Lam DS, Law RW, Wong AK. Phacoemulsification, primary posterior capsulorhexis and capsular intraocular lens implantation for uveitic cataract. J Cataract Refract Surg 1998;24:1111-8.

20. Budak K, Akova YA, Yalvac I, Somer D, Aslan BS, Duman S. Cataract surgery in patients with Fuchs' heterochromic cyclitis. Jpn J Ophthalmol 1999;43:308-11.

21. Heiligenhaus A, Steinmetz B, Lapuente R, Krallmann P, Althaus C, Steinkamp WK, et al. Recombinant tissue plasminogen activator in cases with fibrin formation after cataract surgery: a prospective randomised multicentre study. Br J Ophthalmol 1998;82:810-5.

22. Rehfeldt K, Hoh H. Therapeutic and prophylactic application of TPA (recombinant tissue plasminogen activator) into the anterior chamber of the eye. Ophthalmologe 1999;96:587-93.

23. Foster CS, Lowder CY, Meisler DM, Zakov ZN. Extracapsular cataract extraction and posterior chamber lens implantation in uveitis patients. Ophthalmology 1992;99:1234-41.

24. Akova YA, Foster CS. Cataract surgery in patients with sarcoidosis-associated uveitis. Ophthalmology 1994;101:473-9.

25. Cox SN, Hay E, Bird AC. Treatment of macular oedema with acetozolamide. Arch Ophthalmol 1988;106:1190-5. 